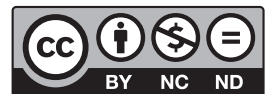

Estudos Teológicos foi licenciado com uma Licença Creative Commons Atribuição - NãoComercial - SemDerivados 3.0 Não Adaptada

http://dx.doi.org/10.22351/et.v58i2.3399

\title{
A decolonialidade da teologia na América Latina E SEUS FUNDAMENTOS BÍBLICOS ${ }^{1}$
}

\author{
The decoloniality of Theology in Latin America and its biblical foundations
}

João Luiz Correia Júnior ${ }^{2}$

Resumo: A decolonialidade, do ponto de vista acadêmico, é uma ferramenta de análise para o estudo crítico da relação entre áreas do conhecimento e colonialidade. Tendo presente esse conceito, o atual trabalho tem como objetivo demonstrar que a teologia desenvolvida na América Latina na segunda metade do século XX contribuiu para o processo de decolonialização da teologia católica e protestante. A partir de fundamentos bíblicos, a teologia desenvolvida na América Latina alicerçou uma reflexão teológica madura e uma prática missionária contextualizada, voltada para enfrentar os desafios socioeconômicos, sociopolíticos e socioculturais do continente latino-americano, que durante séculos foi colonizado pela Europa católica. Trata-se, portanto, de um estudo baseado em pesquisa bíblico-teológica, cujos resultados apontam para o fato de que, na América Latina, surgiu e se desenvolve uma teologia decolonizada, tanto no âmbito católico como no meio protestante.

Palavras-chave: Teologia protestante. Teologia da Libertação. Bíblia. Opção pelos pobres.

Abstract: Decoloniality, from the academic point of view, is an analysis tool for a critical study of the relationship between areas of knowledge and coloniality. With this concept in mind, the present work aims to demonstrate that theology developed in Latin America in the second half of the twentieth century has contributed to the process of decolonialization of Catholic and Protestant theology. Based on biblical foundations, theology developed in Latin America founded a mature theological reflection and contextualized missionary practice, aimed at facing the socio-economic, sociopolitical and sociocultural challenges of the Latin American Continent that for centuries was colonized by Catholic Europe. It is, therefore, a study based on biblical-theological research, whose results point to the fact that, in Latin America, a decolonized theology arose and developed both in the Catholic sphere and in the Protestant milieu.

Keywords: Protestant theology. Liberation Theology. Bible. Option for the poor.

1 O artigo foi recebido em 30 de julho de 2018 e aprovado em 11 de setembro de 2018 com base nas avaliações dos pareceristas ad hoc.

2 Professor titular na Universidade Católica de Pernambuco - UNICAP, onde leciona no Bacharelado em Teologia, no Programa de Mestrado em Teologia e no Programa de Pós-Graduação (Mestrado e Doutorado) em Ciências da Religião. Contato: joaoluizcorreia@uol.com.br 


\section{Introdução}

O tema da decolonialidade é pertinente a todas as áreas do conhecimento. $\mathrm{O}$ presente artigo, dentro deste importante dossiê da revista Estudos Teológicos, não tem como objetivo discutir diretamente sobre o conceito de decolonialidade, mas a partir de uma rápida consideração sobre ele averiguar sua aplicabilidade à teologia que foi e está sendo desenvolvida na América Latina, no âmbito católico e protestante, desde a segunda metade do século XX, com uma especial atenção aos fundamentos bíblicos dessa teologia.

Enfrenta-se o desafio de tratar de uma temática ampla em tão poucas páginas. Justamente por isso solicita-se do leitor não só a compreensão, mas o interesse para que o tema seja mais aprofundado em outras instâncias da pesquisa acadêmica.

Para tanto, o artigo apresenta dois capítulos, em que, no primeiro, defende-se a ideia de que houve e está em curso um árduo trabalho de decolonialidade da teologia na América, e, num segundo capítulo, busca-se apresentar alguns fundamentos bíblicos dessa teologia decolonializada.

Alguns autores e seus conceitos estão citados tanto no campo epistemológico da teologia como no âmbito da pesquisa bíblica. Provavelmente, o leitor perceberá que muitos outros ficaram de fora, mas fica aqui o incentivo para que este artigo-ensaio aguce a curiosidade ao aprofundamento dessa pesquisa.

Passemos, então, à leitura.

\section{A decolonialidade da teologia na América Latina}

O conceito em inglês é decoloniality, e quanto à tradução para espanhol e português não há uma posição unânime. Entretanto, os termos “decolonialidade”, "decolonial" já estão sendo muito usados, suprimindo-se o "s" para marcar uma distinção com o significado de "descolonizar" em seu sentido clássico. Desse modo, salienta-se que a intenção não é desfazer o colonial, ou seja, superar o momento colonial pelo momento pós-colonial. O decolonial implica luta contínua, pois a colonização é um evento prolongado e de múltiplas irradiações. A colonização não diz respeito apenas à administração colonial direta sobre determinadas áreas do mundo, mas refere-se a uma estrutura de dominação que inclui a dimensão do conhecimento. Nesse sentido, fala-se em colonialidade e não apenas de colonialismo, discute-se sobre decolonialidade, e não simplesmente sobre descolonialismo. ${ }^{3}$

A decolonialidade, portanto, enquanto projeto epistêmico, implica ser instrumento de análise da relação entre campos do conhecimento e o fenômeno da colonialidade.

3 Baseio-me aqui na tese de doutorado de DAMÁZIO, Eloise da Silveira Petter. Colonialidade e decolonialidade da (anthropos) logia jurídica: da uni-versalidade à pluri-versalidade epistêmica. 2012. Programa de Pós-Graduação em Direito, Centro de Ciências Jurídicas da Universidade Federal de Santa Catarina, Florianópolis, 2011. p. 19, nota de rodapé 2. Disponível em: $<$ https://repositorio.ufsc.br/bitstream/handle/123456789/95973/299229.pdf?sequence=1\&isAllowed=y>. Acesso em: 31 maio 2018. 
Trata-se de um lugar de crítica à epistemologia eurocêntrica e, consequentemente, dos discursos coloniais. Além disso, a decolonialidade diz respeito também à emergência de distintos saberes que surgem a partir de diferentes espaços de pensamento. ${ }^{4}$

Nessa perspectiva de análise, pode-se afirmar que, na segunda metade do século XX, ocorreu na América Latina uma prática epistemológica que pode ser intitulada de decolonização da teologia tradicional. Isso ocorreu tanto na teologia católica como na teologia protestante, a partir do fecundo trabalho de teólogos interpelados a um novo fazer teológico que enfrentava os desafios do seu contexto social e eclesial. É o que será abordado a seguir.

\section{A decolonialidade na teologia católica na América Latina}

Na Igreja Católica, o Concílio Vaticano II (1962-1965) provocou importante impacto na teologia, fazendo surgir uma "abundante e criativa produção teológica". É o que testemunhou o conhecido teólogo jesuíta João Batista Libânio (1932- 2014):

Os anos conciliares e pós-conciliares foram de uma abundante e criativa produção teológica, recuperando o gigantesco atraso dos séculos de prisão não-escolástica. Vivi em Roma esses primeiros anos conciliares e pós-conciliares, no clima de que tudo é possível em teologia. Havia muita liberdade para pensar e ousar. A personalidade gigantesca de K. Rahner ${ }^{6}$ incentivava-nos a repensar toda uma teologia esclerosada. A virada antropocêntrica colocara a base para avanços ulteriores ${ }^{7}$.

O Concílio Vaticano II oportunizou uma elaboração teológica a partir do contexto latino-americano, enfrentando os desafios desse continente, ainda "reverso da modernidade", para fazer eclodir uma teologia decolonializada da teologia tradicionalista, europeia ou norte-americana.

Nessa perspectiva decolonialista, o teólogo gaúcho Hugo Assmann (19332008), inspirado no teólogo uruguaio Juan Luís Segundo (1925-1996), defendeu a proposição de que "cabe aos teólogos latino-americanos, como tarefa primordial, a

4 DAMÁZIO, 2011, página do RESUMO.

5 O Concílio Ecumênico Vaticano II foi convocado, em 1961, pelo papa João XXIII e inaugurado em 1962. O Concílio foi concluído em 1965, já sob o papado de Paulo VI. Realizado no Vaticano, tinha como objetivo promover o aggiornamento (atualização) e abertura da Igreja Católica Romana.

6 Karl Josef Erich Rahner (1904-1984) foi um padre jesuíta de origem germânica e um dos mais influentes teólogos do século XX. Para muitos especialistas, sua teologia marca a entrada da Igreja Católica na modernidade. A teologia de Rahner representa a contribuição mais vigorosa, no âmbito da teologia católica, para aquela que foi definida como a "reviravolta antropológica" em teologia, a qual tem, no âmbito da teologia protestante, suas figuras principais na teologia existencial de Rudolf Karl Bultmann (teólogo luterano alemão, 1884-1976) e no método da correlação de Paul Johannes Oskar Tillich (teólogo alemão-estadunidense e filósofo da religião, 1886-1965). GIBELLINI, Rosino. A Teologia do século XX. São Paulo: Loyola, 1998. p. 237.

7 LIBANIO, João Batista. Trinta anos de Teologia: reflexão pessoal. In: SUSIN, Luiz Carlos (Org.). O mar se abriu. Trinta anos de teologia na América Latina. São Paulo: Loyola, 2000. p. 139. 
libertação da teologia porque, sem isto, não pode haver Teologia da Libertação"». E acrescentou: "A teologia precisa romper com teorias lineares, tradicionais, europeias, e entender algo de sistemas dinâmicos e complexos nos quais a auto-organização e os novos níveis emergentes cumprem um papel fundamental"9.

Desse modo, a teologia decolonizada, a partir dos desafios contextuais da América Latina, encara de frente questões antropológicas fundamentais, que levam ao confronto com a impossibilidade de soluções perfeitas e definitivas, mas, também, que levam à plausibilidade de esperanças tópicas, possíveis de serem concretizadas.

\section{A decolonialidade na teologia protestante na América Latina}

A teologia cristã, católica ou protestante, tem como princípio material a missão evangelizadora. É nessa perspectiva que um importante teólogo argentino, de tradição protestante (metodista), José Míguez Bonino (1924-2012), já afirmava: “Admitir que missão-evangelização é o princípio que define o protestantismo latino-americano nos envolve de imediato na ambiguidade histórica e teológica desse movimento. Qual é a relação entre missão e colonialismo?"'10. E acrescenta a esse questionamento a seguinte constatação:

A evangelização que alcança a América Latina a partir do século 19 se inscreve, com efeito, na totalidade da empresa missionária do protestantismo europeu - em nosso caso, particularmente do anglo-saxão - nos séculos 18 e 19. E hoje em dia já é um lugar comum recordar que essa missão avança na crista da expansão colonial e neocolonial e carrega as marcas dessa relação ${ }^{11}$.

Tendo presente essa contribuição de Bonino, pode-se inferir que a teologia protestante latino-americana foi marcada pela teologia que fundamentou o modelo missionário do protestantismo europeu (diretamente de lá, ou através dos Estados Unidos). Essa teologia fundamentou uma ética individual e não social.

O conhecido teólogo Rubem Azevedo Alves (1933-2014), ao tratar da ética social protestante em seu livro "Protestantismo e Repressão", publicado em 1979, já afirmava que esse protestantismo tradicional "nunca articulou, espontaneamente, uma ética social [...] Foi em decorrência de pressões exteriores que começou a falar sobre $\mathrm{o}$ assunto" 12 . E explica quais foram os fatores que provocaram a igreja para que falasse sobre ética social:

A tomada de consciência dos problemas sociais e econômicos em nosso país, na década dos anos 50. O problema da pobreza, das desigualdades, das injustiças; a consciência de

\footnotetext{
8 ASSMANN, Hugo. Por uma Teologia humanamente saudável: fragmentos de memória pessoal. In: SUSIN (Org.), 2000, p. 117.

9 ASSMANN, 2000, p. 121 e 127.

${ }^{10}$ BONINO, José Míguez. Rostos do Protestantismo Latino-Americano. São Leopoldo: Sinodal, 2002. p. 117.

11 BONINO, 2002, p. 117.

12 ALVES, Rubem A. Protestantismo e Repressão. São Paulo: Ática, 1979. p. 216.
} 
nossa condição de país subdesenvolvido, país politicamente livre, mas economicamente à mercê dos centros de decisão política e econômica estrangeiros...

A influência teológica que nos vinha, pela primeira vez, da Europa. Até então a influência teológica norte-americana, ou, mais precisamente, missionária e pietista, não tinha competidores. O novo pensamento foi avidamente recebido pelos jovens e pelos estudantes nos seminários ${ }^{13}$.

Seguindo essa linha do raciocínio histórico de Rubem Alves, importante lembrar que, na década de 70 do século XX, observou-se em igrejas de tradição protestante o surgimento de um fazer missionário que procurava considerar o contexto social do indivíduo, intitulado de Missão Integral. Esse movimento ressaltava a pertinência entre evangelização e responsabilidade social, e recebeu importante influência dos teólogos latino-americanos presentes no Congresso de Lausanne ${ }^{14}$. Um deles foi o equatoriano René Padilla (1932-) ${ }^{15}$. Em seu livro "Missão Integral”, o teólogo afirma:

O conceito de igreja como entidade "separada" do mundo se presta a toda sorte de falsas interpretações. Num extremo está a posição em que a separação não passa de uma simples distinção epistemológica: a igreja sabe que foi reconciliada com Deus, o mundo não sabe - e isto é tudo. No outro extremo está a posição segundo a qual a separação é um abismo intransponível entre duas cidades que somente se comunicam entre si em termos de uma cruzada por parte de uma para conquistar a outra. A maneira de entender a natureza da separação entre o mundo e a igreja inevitavelmente incide em nossa definição do evangelho e em nossos métodos de evangelização. Urge a recuperação de uma evangelização que faça justiça ao binômio mundo/igreja, visto na perspectiva da escravidão da igreja ao mundo ${ }^{16}$.

Percebe-se, aqui, em Padilla, uma teologia (mais especificamente eclesiológica) marcada por uma decolonialidade, por um afastamento epistemológico da teologia tradicionalmente reconhecida como oficial, de cunho fundamentalista.

Esse fazer teológico e eclesiológico que remonta às raízes da genuína tradição bíblica de compromisso com a libertação (tradição do Êxodo) e da construção do reino de Deus (tradição evangélica) teve uma repercussão positiva. Em novembro de 1979, a Fraternidade Teológica Latino-Americana realizou o II Congresso Latino-Americano de Evangelização - CLADE II, em Lima, Peru. Em 1983, no I Congresso Brasileiro de Evangelização (CBE-83), realizado em Belo Horizonte, já se afirmava

13 ALVES, 1979, p. 216-217.

14 O Congresso Internacional de Evangelização Mundial, realizado em Lausanne, Suíça, em 1979, elaborou um Pacto que teve como redator final o teólogo anglicano britânico John Stott (1921-2011). Foi assinado pelas 2.700 pessoas presentes, provenientes de 150 nações. O Pacto de Lausanne se destaca pela sua abrangência (aborda 15 temas) e pela ênfase na evangelização com responsabilidade social. AQUINO, Rodrigo Bibo. Missão Integral em poucas palavras. Joinville: BTBook’s, 2013. p. 4-5; 7. Disponível em: $<$ http://bibotalk.com.br/textos/missaointegral.pdf>. Acesso em: 02 jun. 2018.

15 C. René Padilla, nascido em 1932 em Quito, Equador, é um teólogo e missiólogo evangélico, um dos precursores da missão integral nos anos 1970, por articular a dupla prioridade do cristianismo na evangelização e no compromisso social.

16 PADILLA, C. René. Missão integral: ensaios sobre o Reino e a Igreja. Londrina: Descoberta, 2005. p. 22-23. 
que o Pacto de Lausanne desencadeou um movimento de evangelização de grupos humanos concretos, que antes não contavam com a presença cristã significativa, como também deu impulso a uma reflexão teológica sobre assuntos relacionados com a evangelização do mundo. Vinte anos depois, em 2003, é realizado o II Congresso Brasileiro de Evangelização, também em Belo Horizonte. Embora se reconheça que o Brasil ainda está aprendendo a fazer Missão Integral, a marca do congresso foi o incentivo em praticá-la como compromisso com o Evangelho de Jesus Cristo, que se expressa no amor pela terra, pela gente e pela cultura brasileira. ${ }^{17}$

Tendo presente essa breve retrospectiva histórica sobre a teologia latino-americana da segunda metade do século XX, pode-se afirmar que, tanto no meio católico como no âmbito das igrejas protestantes, encontramos o surgimento de uma concepção teológica divergente da tradicional que intitulamos aqui de teologia decolonizada.

Teólogos(as) conservadores(as) fundamentalistas continuaram defendendo que a prioridade teológica e missionária consiste unicamente no anúncio de Jesus Cristo, enquanto uma teologia divergente, problematizada pelos desafios contemporâneos, começou a trabalhar na compreensão de que tanto o anúncio de Jesus Cristo como a ação social se completam, sem uma ordem de prioridade entre elas.

Desencadeia-se, então, um processo de decolonialidade da teologia, inclusive no âmbito da teologia da missão, missiologia, cujas repercussões práticas se observam no modo de ser igreja, inserida no compromisso de mudar a realidade social, trabalhando em prol da construção do reino de Deus, em pleno contexto de exclusão e conflitos da América Latina.

A seguir, serão apresentados alguns fundamentos bíblicos e os principais pesquisadores da prática de decolonialidade trabalhada na teologia latino-americana.

\section{Fundamentos bíblicos da teologia decolonizada na América Latina}

A teologia tradicionalmente elaborada na América Latina, católica e protestante fora preponderantemente alicerçada numa abordagem fundamentalista da Bíblia, que interpreta os escritos numa perspectiva "espiritualista", em que a salvação se dá numa região "espiritual", num "outro mundo". Trata-se de uma cosmovisão dualista em que a realidade material é dissociada da espiritual.

De acordo com o teólogo porto-riquenho Samuel Silva Gotay (1935-) $)^{18}$, por meio dessa visão dualista, os aspectos urgentes da vida tais como a justiça, o pão,

17 AQUINO, 2013, p. 8-9.

18 Samuel Silva Gotay é um sociólogo da religião de Porto Rico e América Latina. Ele nasceu em Ponce, Porto Rico, em 1935. Criado em uma tradição protestante, ele se tornou ativo no movimento ecumênico durante seus dias de estudante. Em 1955, tornou-se membro do Comitê Executivo da World Christian Student Federation, o mais antigo movimento ecumênico do mundo. Ele é graduado pela Universidade de Porto Rico, pela Universidade de Yale e pela Universidade Nacional Autônoma do México, onde realizou estudos de Psicologia, Teologia e Estudos Latino-Americanos. Lecionou na Faculdade de Ciências Sociais da Universidade de Porto Rico, Campus Rio Piedras, e coordenou o projeto de História Social da igreja no Caribe para o CEHILA - Comissão de Estudos de História da Igreja na América Latina e no Caribe, 
a ação solidária de devolver a vista aos cegos, a liberdade aos oprimidos, a paz aos aflitos e a realização das promessas do reino de Deus foram de tal modo espiritualizadas que passam a impressão de que a Bíblia não se refere a "este mundo", mas a "um outro". O pão, a justiça e a libertação perderam sua urgência para o aqui e agora da realidade material e passaram a ser ressaltados como promessa para o além. Por causa da teologia fundamentalista dessas igrejas, suas pregações se esforçam para admoestar os fiéis e as massas a se resignarem a esperar que essas promessas sejam atendidas no "outro mundo", depois da morte, suportando e mantendo as condições existentes na terra tal como estão. A consequência disso é uma des-historização da própria história real registrada na Bíblia. ${ }^{19}$

A elaboração teológica decolonializada marca, portanto, o enfrentamento dessa teologia tradicionalmente seguida no continente latino-americano. Para tanto, buscaram-se fundamentos numa hermenêutica bíblica que revaloriza a concepção historicizada do pensamento bíblico, à luz da visão hebraica do mundo, em que não há dicotomia entre realidade material e realidade espiritual: Deus intervém na história por meio de uma aliança com o povo de Israel, num projeto histórico de libertação sociopolítica e econômica, narrada a partir da experiência do êxodo. ${ }^{20}$

Muitos biblistas, homens e mulheres latino-americanos, deram notáveis contribuições para o aprofundamento dessa hermenêutica decolonializada na América Latina. Dentre essas pessoas não se pode esquecer a contribuição do argentino Severino Croatto (1930-2004), da mexicana Elsa Tamez (1950-), dos brasileiros Milton Schwantes (19462012) e Carlos Mesters (1931-), entre tantos outros. A hermenêutica que estava sendo elaborada por essas e outras pessoas, pesquisadoras da Bíblia na América Latina, encontrou na releitura do êxodo a centralidade da teologia bíblica. Como recorda o biblista Valmor da Silva, em 1971, o teólogo e filósofo mexicano José Porfírio Miranda (19242001) apresentou sua crítica histórica da opressão, em chave declaradamente marxista, para provar como a causa principal de Deus, ao longo de toda a Bíblia, é a luta pela

e para o Instituto de Estudos do Caribe, dessa faculdade. GOTAY, Samuel Silva. O pensamento cristão revolucionário na América Latina e no Caribe (1960-1973): implicações da Teologia da Libertação para a Sociologia da Religião. São Paulo: Paulinas, 1985. Informações na contracapa do livro.

19 GOTAY, 1985, p. 123-124.

${ }^{20}$ Segundo Gotay, essa interpretação bíblica, à luz da visão hebraica do mundo, foi um trabalho iniciado por exegetas europeus, a partir do século XIX, mas sua aplicação à vida contemporânea ainda está contaminada pela perspectiva liberal da sociedade capitalista europeia e, ultimamente, norte-americana. Há anos vem-se procurando desmitificar a Bíblia, mas sem levar suas implicações políticas até suas últimas consequências. Detém-se o processo na interpretação subjetiva da teologia existencialista. Não se faz uma hermenêutica política. É a teologia da libertação que redescobre em sua realidade toda a implicação sociopolítica dos textos bíblicos. Essa hermenêutica bíblica latino-americana respeita os termos históricos dos acontecimentos. Nela, o novo entendimento científico do ser humano como ser social permite a recuperação do significado hebreu-cristão, originário dos textos. A história bíblica demonstra, nessa releitura, que os atos do povo que mantém a fidelidade à aliança são atos de libertação históricas, e, como tais, são atos sociopolíticos. Demonstra também que a salvação "pessoal" está atrelada ao empenho na construção do reino de Deus, acontecimento histórico e coletivo. Isso é, sem dúvida, uma hermenêutica decolonializada das interpretações espiritualizadas que des-historicizam a realidade bíblica e que reduzem a fé cristã a uma religião interior com foco na vida privada ou que inibe a participação política do cristão no processo de mudança social. GOTAY, 1985, p. 125. 
justiça. De acordo com Porfírio, na experiência bíblica do êxodo, o plano de Iahweh é claro, no sentido de implantar uma situação de justiça na terra. Isso se torna evidente no Gênesis, apresentado como prólogo ao Êxodo, bem como nos profetas, nos salmos e nos evangelhos, pois "a intervenção de Deus em nossa história tem como única finalidade realizar a justiça na terra". Israel está convicto de que o seu Deus é aquele que ouve o clamor dos oprimidos para estabelecer a justiça (Is 46.12-13). ${ }^{21}$

Nessa linha hermenêutica que ressalta o grau de importância do estudo bíblico do êxodo de Israel, o biblista Severino Croatto, como bem recorda Samuel Gotay ${ }^{22}$, já ressaltava em seu livro Liberación y liberdade, publicado em 1972, que o êxodo foi, por excelência, "a" experiência salvífica de Israel.

Numa outra obra, de 1978, publicada em 1981 no Brasil, "Êxodo: uma hermenêutica da liberdade" ${ }^{23}$, Severino Croatto retoma e aprofunda a ideia acima. Em um comentário sobre esse livro, Valmor da Silva considera-o como um "marco histórico na hermenêutica bíblica latino-americana", e acrescenta:

Esta obra dá um aparato acadêmico à nossa leitura do Êxodo e estabelece um diálogo com outros estudos, principalmente com os filósofos da linguagem. As narrativas bíblicas são apresentadas como memória de fatos e como geradoras de novos acontecimentos. Daí conterem sempre uma "reserva-de-sentido". Os vários elementos da libertação do Egito são avaliados de maneira crítica, sendo que o grito dos escravos ganha especial destaque por levar à descoberta do Deus libertador ${ }^{24}$.

Desse modo, a mensagem central da Bíblia é interpretada como ação salvífica de Deus na história do povo de Israel. Foi a partir das próprias memórias do passado que esse povo elaborou uma reflexão teológica em que seu Deus é enfatizado pelo protagonismo salvífico que exerce. Por meio de uma aliança religiosa de cunho eminentemente político, soergue e empodera esse povo escravizado no Egito para lutar por sua própria libertação. Como ação vitoriosa, a memória foi preservada nos credos de Israel, tal como se pode encontrar em diversas passagens da Bíblia (Dt 6.20-25; 26.5-10; Js 24.2-13).

A experiência da ação salvífica de Deus, na genuína tradição bíblica, equivale, portanto, à experiência de "libertação" histórica: Deus é compreendido dentro de uma aliança salvífica, porque age de forma vitoriosa e libertária na história. Nessa perspectiva, o teólogo peruano Gustavo Gutiérrez (1928-), um dos pais da Teologia da Libertação, afirma:

a noção de salvação revela uma faceta que não aparecia na perspectiva anterior. A salvação não é algo "ultra-mundano", ante o qual a vida presente seria apenas uma prova.

\footnotetext{
${ }^{21}$ SILVA, Valmor da. Leituras do Êxodo na América Latina. In: REIMER, Haroldo; SILVA, Valmor da (Orgs.). Libertação - liberdade. Novos olhares: contribuições ao II Congresso Brasileiro de Pesquisa Bíblica. São Leopoldo: Oikos; Goiânia: UCG, 2008. p. 20-21.

22 GOTAY, 1985, p. 125-126.

${ }^{23}$ CROATTO, José Severino. Exxodo - uma hermenêutica da liberdade. São Paulo: Paulinas, 1981.

${ }^{24}$ SILVA, 2008, p. 22.
} 
A salvação - comunhão dos homens com Deus e comunhão dos homens entre si - é algo que se dá também, real e concretamente, desde agora, que assume toda a realidade humana, a transforma e a leva à sua plenitude em Cristo [...] Esta plenitude envolve o homem e sua totalidade: corpo e espírito, indivíduo e sociedade, pessoa e cosmos, tempo e eternidade ${ }^{25}$.

A experiência religiosa de salvação / libertação, na Bíblia, surge, portanto, a partir de um evento histórico bem objetivo: a escravidão no Egito. Aprofundando-se ainda mais nesse aspecto, a biblista mexicana, de tradição metodista, Elsa Tamez chegou a desenvolver o tema da "opressão". Em 1979 publicou a obra "La biblia de los oprimidos: la opresión en la teología bíblica"26.

O tema da "opressão" abre um novo horizonte para a hermenêutica bíblica latino-americana decolonializada. Nesse livro, no capítulo II, a autora adverte que, ao se tratar da opressão na Bíblia ou em qualquer contexto, deve-se procurar identificar os atores, quer sejam executores quer sejam receptores da opressão. Do contrário, corre-se o risco de considerar a opressão como um tema a mais, sem analisar a fundo os motivos, as ações e os sujeitos que produzem esse estado perverso de injustiça. ${ }^{27}$ Elsa Tamez deixa claro que a opressão na Bíblia está estampada nas pessoas empobrecidas, nos homens e mulheres escravizados, nos diaristas, nas viúvas, nos órfãos, nos imigrantes e em todos os pobres, sem prestígio e sem poder, porém com a fé viva de que Iahweh, o Deus da Bíblia, é justiça e amor e que sua justiça se manifesta, produzindo uma transformação radical: suas terras serão devolvidas, o fruto de suas colheitas será para eles, habitarão em casas que construíram, serão ouvidos nos tribunais, não sofrerão perseguição nem serão encarcerados, serão libertados; em outras palavras, se celebrará de forma autêntica a festa do jubileu, o ano da graça do Senhor. ${ }^{28}$

Elsa Tamez também ficou conhecida como importante teóloga e biblista feminista latino-americana. Em 1980 publicou o artigo "La mujer que complicó la historia de la salvación", que reflete sobre a figura bíblica de Agar. Em seguida, veio o "El rostro femenino de Dios", que consolidava reflexões de um encontro de teólogas latino-americanas realizado na Argentina em 1985. Tal como Elsa, outras biblistas brasileiras também se notabilizaram pela pesquisa bíblica. Ressalto, dentre tantas, Ivoni Richer Reimer e Nancy Cardoso Pereira, ambas de tradição protestante. A hermenêutica feminista latino-americana contribuiu para a teologia feminista, que tem em Ivone Gebara um nome bastante conhecido. Como companheira da hermenêutica feminista decolonializada na América Latina, não se pode esquecer a grande Elisabeth Schüssler-Fiorenza (1938-), teóloga natural da Romênia, que lecionou na Harvard

${ }^{25}$ GUTIÉRREZ, Gustavo. Teologia da Libertação. Petrópolis: Vozes, 1979. p. 127-128.

${ }^{26}$ O livro foi publicado no Brasil. TAMEZ, Elsa. A Bíblia dos oprimidos: a opressão na teologia bíblica. São Paulo: Paulinas, 1980. A edição original está disponível em: $<$ https://archive.org/details/labibliadelosopr00tame>.

27 TAMEZ, Elsa. La biblia de los oprimidos: la opresión en la teología bíblica. San Jose de Costa Rica: DEI (Departamento Ecuménico de Investigaciones), 1979. p. 65. Disponível em: <https://archive.org/details/ labibliadelosopr00tame>. Acesso em: 29 jul. 2018.

28 TAMEZ, 1979, p. 119. 
Divinity School, que é uma das escolas constituintes da Universidade de Harvard, localizada em Cambridge, Massachusetts, Estados Unidos.

Outra pessoa importante para a hermenêutica bíblica latino-americana foi o gaúcho luterano Milton Schwantes, que, como professor e autor, dedicou-se aos estudos do Antigo Testamento numa perspectiva libertadora. O biblista chileno Pablo Richard, no livro "Dimensões sociais da fé do Antigo Testamento: uma homenagem a Milton Schwantes", definiu a vida de Milton em sete palavras: Exegese - Hermenêutica - Bíblia - Esperança - Pobres - Libertação - Ecumenismo. E destaca: "Milton sempre fez a relação entre exegese eclesial acadêmica e exegese pastoral e libertadora" 29 .

Preocupado com a divulgação dos estudos bíblicos latino-americanos, Milton Schwantes empenhou-se em colaborar com a Revista de Interpretação Bíblica Latino-Americana - RIBLA. Esteve presente em sua fundação, juntamente com Carlos Mesters, Jorge Pixley, Pablo Richard, dentre outros. O primeiro número foi publicado em 1988, com o título muito significativo: "Lectura Popular de la Biblia en America Latina. Una hermenêutica de Liberación". Era todo um programa de trabalho para o futuro: difundir a pesquisa em forma de artigos a partir da hermenêtica latino-americana decolonializada. A apresentação desse número da RIBLA foi escrita por Milton Schwantes, que ressaltou: "As dores, utopias e poesias dos pobres se tornaram, através das comunidades, mediações hermenêuticas decisivas para a leitura da Bíblia na América Latina e no Caribe" ${ }^{30}$.

Tão empenhado quanto Milton Schwantes na produção e difusão da hermenêutica latino-americana foi o biblista Carlos Mesters (1931-). Ele e outros biblistas de igrejas cristãs comprometidas com a pesquisa bíblica decolonializada fundaram o Centro de Estudos Bíblicos - CEBI. Essa instituição tem como objetivo divulgar, aprimorar e capacitar pessoas no uso dessa nova forma (metodologia) de ler e interpretar a Bíblia. Esse centro de estudos foi fundado em 20 de julho de 1979 como associação ecumênica sem fins lucrativos, formada por mulheres e homens de diversas denominações cristãs. ${ }^{31} \mathrm{O}$ CEBI tem sido importante meio de difusão da pesquisa bíblica no Brasil, em âmbito acadêmico e popular.

Nessa perspectiva de pesquisa e publicação da hermenêutica bíblica produzida na América Latina, é importante ressaltar a contribuição do Comentário Bíblico, que durante muitos anos foi publicado pela Editora Vozes. ${ }^{32}$ Esse comentário contou com o labor de biblistas como Sandro Gallazi, Severino Croatto, Sebastião Armando Gameleira, Ney Brasil Pereira, Luiz Dietrich, Francisco Orofino, Milton Schwantes, Valmor da Silva, Joel Ferreira, Gilberto Gorgulho, Ivoni Richter Reimer e Haroldo

29 RICHARD, Pablo. Milton Schwantes: un obrero de la lectura popular de la Biblia em América Latina y el Caribe. En reconocimiento a su vida e su trabajo. In: KAEFER, José Ademar; JARSCHEL, Haidi (Orgs.). Dimensões Sociais da fé do Antigo Testamento: uma homenagem a Milton Schwantes. São Paulo: Paulinas, 2007. p. 14-15.

30 RICHARD, 2007, p. 14-15.

31 Essas informações se encontram no próprio site do CEBI, no link "história". Disponível em: <https:// www.cebi.org.br/historia/>. Acesso em: 29 jul. 2018.

32 A coleção, posteriormente, passou a ser coeditada com a Sinodal, do Rio Grande do Sul, e, em seguida, pela Fonte Editorial, de São Paulo. 
Reimer, dentre outros pelo notório saber na área, como José Comblin. Conforme está escrito na contracapa de um dos livros editados, a coleção "Comentário Bíblico"

Nasceu de uma leitura nova da Bíblia feita pelo próprio povo cristão que vive aperreado e anseia por uma situação melhor e mais fraterna. Um grupo de biblistas católicos e protestantes, que trabalham há tempo com o povo e querem pensar os seus problemas, decidiu pôr no papel a interpretação que os pobres fazem da Bíblia. Sem abordar a sua formação científica, tentam mostrar o sentido que os pobres gostam de exprimir, mas não são capazes por falta de estudo e recursos. Apresentam, assim, um comentário prático, pastoral, e que reforça a caminhada dos pobres. Estes livros se destinam principalmente aos agentes de pastoral, líderes comunitários, coordenadores de círculos bíblicos e a todos os que simpatizam com o povo simples e se interessam por seu destino. Duas editoras se associaram neste empreendimento: Editora Vozes (católica) e a Editora Sinodal (luterana). A coleção constará de uns 70 fascículos ${ }^{33}$.

Por fim, é importante salientar também que é digna de nota a contribuição prestada à hermenêutica latino-americana pela revista Estudos Bíblicos, da Editora Vozes, tendo como editor responsável o Frei Ludovico Garmus, além de competente conselho editorial, que conta com a contribuição de biblistas católicos e protestantes. Por meio de artigos dentro de temáticas específicas, a revista é publicada quatro vezes ao ano, e tem sido muito utilizada na pastoral bíblica e em sala de aula, nos cursos de graduação em Teologia.

\section{Considerações finais}

Não se pode esquecer que, na América Latina, igrejas e setores de igrejas envolvidas no conservadorismo subsidiaram e subsidiam ainda hoje argumentos ideológicos que as mantêm em sua zona de conforto, cada vez mais fechadas em si mesmas. Amedrontadas diante dos inúmeros desafios do secularismo e da indiferença religiosa do mundo atual, cultivam expectativas carismáticas messiânicas de cunho escatológico, totalmente alienadas do entorno social. Esse fenômeno tem, inclusive, ressurgido com muita intensidade no final do século XX e princípio do século XXI, quando ondas de conservadorismo voltam a aparecer em toda parte.

Contudo, a teologia latino-americana, bem alicerçada numa hermenêutica bíblica decolonializada, fincou raízes na formação teológica e bíblica de homens e mulheres, alguns dos quais citados nesse artigo, sensibilizados com a causa do sofrido povo de nosso continente. Essas pessoas, hoje, lecionam e pesquisam no campo epistemológico da teologia, e da Bíblia, em programas de mestrado e doutorado em Teologia e Ciências da Religião em universidades católicas e protestantes do Brasil e

${ }^{33} \mathrm{O}$ livro editado em que aparece na contracapa o texto citado é: CROATTO, J. Severino. Isaías - A palavra profética e sua releitura hermenêutica. Trad. Haroldo Reimer. Petrópolis: Vozes; São Leopoldo: Sinodal, 1998. contracapa. (v. II: 40-55: A libertação é possível). 
de outros países. Há, inclusive, muitos que fazem ecoar seus estudos acadêmicos para suas respectivas igrejas e movimentos eclesiais.

Pode-se inferir, a partir deste breve artigo, que a teologia e a hermenêutica bíblica decolonializadas continuam vivas no continente latino-americano, disseminadas - de muitos modos - em diferentes setores da sociedade, com forte poder político desalienador e libertador. Fica, portanto, o desafio para que seja ainda mais estudada e a pesquisa continue sendo aprofundada.

\section{Referências}

ALVES, Rubem A. Protestantismo e Repressão. São Paulo: Ática, 1979.

AQUINO, Rodrigo Bibo. Missão Integral em poucas palavras. Joinville: BTBook's, 2013. Disponível em: <http://bibotalk.com.br/textos/missaointegral.pdf > . Acesso em: 02 jun. 2018.

ASSMANN, Hugo. Por uma Teologia humanamente saudável: fragmentos de memória pessoal. In: SUSIN, Luiz Carlos (Org.). O mar se abriu. Trinta anos de teologia na América Latina. São Paulo: Loyola, 2000.

CROATTO, J. Severino. Isaías - A palavra profética e sua releitura hermenêutica. Trad. Haroldo Reimer. Petrópolis: Vozes; São Leopoldo: Sinodal, 1998. contracapa. (v. II: 40-55: A libertação é possível).

CROATTO, José Severino. Exxodo - uma hermenêutica da liberdade. São Paulo: Paulinas, 1981. BONINO, José Míguez. Rostos do Protestantismo Latino-Americano. São Leopoldo: Sinodal, 2002. SILVA, Valmor da. Leituras do Êxodo na América Latina. In: REIMER, Haroldo; SILVA, Valmor da (Orgs). Libertação - liberdade. Novos olhares: contribuições ao II Congresso Brasileiro de Pesquisa Bíblica. São Leopoldo: Oikos; Goiânia: UCG, 2008.

DAMÁZIO, Eloise da Silveira Petter. Colonialidade e decolonialidade da (anthropos)logia jurídica: da uni-versalidade a pluri-versalidade epistêmica. 2011. Programa de Pós-Graduação em Direito, Centro de Ciências Jurídicas da Universidade Federal de Santa Catarina, Florianópolis, 2011. Disponível em: <https://repositorio.ufsc.br/bitstream/handle/123456789/95973/299229. pdf? sequence $=1$ \&isAllowed $=\mathrm{y}>$. Acesso em: 31 maio 2018.

GIBELLINI, Rosino. A Teologia do século XX. São Paulo: Loyola, 1998.

GOTAY, Samuel Silva. O pensamento cristão revolucionário na América Latina e no Caribe (1960-1973): implicações da Teologia da Libertação para a Sociologia da Religião. São Paulo: Paulinas, 1985.

GUTIÉRREZ, Gustavo. Teologia da Libertação. Petrópolis: Vozes, 1979.

LIBANIO, João Batista. Trinta anos de Teologia: reflexão pessoal. In: SUSIN, Luiz Carlos (Org.). O mar se abriu. Trinta anos de teologia na América Latina. São Paulo: Loyola, 2000.

PACTO DE LAUSANNE. Disponível em: < http://www.monergismo.com/textos/credos/Pacto_de_Lausanne.pdf $>$. Acesso em: 02 jun. 2018.

PĀDILLLA, C. René. Missão integral: ensaios sobre o Reino e a Igreja. Londrina: Descoberta, 2005. RICHARD, Pablo. Milton Schwantes: un obrero de la lectura popular de la Biblia en América Latina y el Caribe. En reconocimiento a su vida e su trabajo. In: KAEFER, José Ademar; JARSCHEL, Haidi (Orgs.). Dimensões Sociais da fé do Antigo Testamento: uma homenagem a Milton Schwantes. São Paulo: Paulinas, 2007.

TAMEZ, Elsa. A Bíblia dos oprimidos: a opressão na teologia bíblica. São Paulo: Paulinas, 1980. . La biblia de los oprimidos: la opresión en la teología bíblica. San Jose de Costa Rica: DEI (Departamento Ecuménico de Investigaciones), 1979. Disponível em: <https://archive.org/ details/labibliadelosopr00tame>. Acesso em: 29 jul. 2018. 